\title{
Chemical and nutritional characterization of Chenopodium quinoa Willd (quinoa) grains: A good alternative to nutritious food
}

\author{
Eliana Pereira ${ }^{\mathrm{a}}$, Christian Encina-Zelada ${ }^{\mathrm{a}, \mathrm{b}}$, Lillian Barros ${ }^{\mathrm{a}}$, Ursula Gonzales-Barron ${ }^{\mathrm{a}}$, \\ Vasco Cadavez ${ }^{\mathrm{a}}$, Isabel C.F.R. Ferreira ${ }^{\mathrm{a}, *}$ \\ ${ }^{a}$ Centrode Investigação de Montanha (CIMO), Instituto Politécnico de Bragança, Campus de Santa Apolónia, 5300-253 Bragança, Portugal \\ ${ }^{\mathrm{b}}$ Departmentof Food Technology, Faculty of Food Industries, National Agricultural University La Molina, Lima, Peru
}

\section{A R T I C L E I N F O}

\section{Keywords:}

Chenopodium quinoa Willd

Quinoa

Nutritional value

Chemical composition

\begin{abstract}
A B S T R A C T
With the purpose of valuing the species Chenopodium quinoa Willd (quinoa), as well as encouraging the consumption of its grains, this study aimed at providing a detailed evaluation of the nutritional value and chemical composition of several quinoa grains of different colour varieties (black, red and white) from different origins. The results demonstrated an excellent composition, namely in the presence of many compounds of interest, such as organic acids, tocopherols and unsaturated fatty acids, as well as a very favourable nutritional profile, with carbohydrates and proteins being the prominent macronutrients. Regarding the different varieties, statistical analysis showed that there were no significant differences in studied parameters, with the exception of proteins, carbohydrates, oxalic acid, $\gamma$-tocopherol and total tocopherols content. Thus, this pseudocereal takes a position of nutritional excellence, compared to others cereals more commonly consumed, thereby representing a promising ingredient for many uses in the food industry.
\end{abstract}

\section{Introduction}

The practice of healthier lifestyles has increased, namely by changing eating habits, opting for foods rich in bioactive compounds. In addition to nutritional satisfaction, consumers seek for food that also provides health and wellness benefits (Küster \& Vila, 2017). One of the crops that have attracted much attention in recent times is Chenopodium quinoa Willd (quinoa) (Navruz-Varli \& Sanlier, 2016). This species, belongs to the Chenopodiaceae family, and has been cultivated for centuries in the Andean countries of Peru and Bolivia (Encina-Zelada et al., 2017); however, nowadays their cultivation has spread to several countries, such as Australia, Canada, China, England and others ( $\mathrm{Hu}$ et al., 2017; Aziz, Akram, \& Ashraf, 2018). This could happen because quinoa has a high resistance to abiotic stresses, since these plants have a great genetic variability that allows their adaptation and growth in the most adverse environmental conditions (Abderrahim et al., 2015; Navruz-Varli \& Sanlier, 2016; Aziz et al., 2018; Li \& Zhu, 2018).

Quinoa is known as pseudocereal because, although not belonging to the Gramineae family, it produces seeds that can be milled into flour and used as a cereal crop (Encina-Zelada et al., 2017; Vilcacundo \& Hernández-Ledesma, 2017). Despite not being as widespread as wheat or rye, the interest in its consumption has grown progressively due to its attractive nutritional composition. Quinoa seeds reveal total absence of gluten, high levels of fatty acids, vitamins, minerals, dietary fibers, and proteins with more amino acids (Gómez-Caravaca, Iafelice, Verardo, Marconi, \& Caboni, 2014; Abderrahim et al., 2015; Tang et al., 2015; Aziz et al., 2018; Pellegrini et al., 2018). In addition to this rich nutritional composition, these seeds have been found to contain a large variety of bioactive compounds, such as carotenoids, vitamin $\mathrm{C}$ and phenolic compounds, which are evident in many studies as protective against a variety of diseases, particularly cancer, allergy, inflammatory diseases, and may reduce the risk of cardiovascular diseases, considering quinoa seeds a functional food (Gómez-Caravaca et al., 2014; Nowak, Du, \& Charrondière, 2016).

There are several forms of consumption of quinoa; namely, the seeds can be fermented to make beer; the germinated seedlings (quinoa sprouts) can be incorporated in salads; and even the whole plant can be used as a rich nutritional source to feed livestock (Vilcacundo \& Hernández-Ledesma, 2017). Since these seeds can also be milled in flour, it can be used for the same purpose as cereals, such as pastry and bakery products (Gómez-Caravaca et al., 2014; Vilcacundo \& Hernández-Ledesma, 2017).

Some scientific studies have been developed to characterize Chenopodium quinoa Willd; however, this study intends to make a

\footnotetext{
* Corresponding author.

E-mail address: iferreira@ipb.pt (I. C.F.R. Ferreira).
} 
Table 1

Characterization of Chenopodium quinoa Willd varieties analysed.

\begin{tabular}{|c|c|c|c|}
\hline Sample code & Colour & Provenience & Origin \\
\hline Q1 & White & Commercial-unknown & Spain \\
\hline Q2 & White & Commercial-unknown & Peru \\
\hline Q3 & Red & Commercial-unknown & Peru \\
\hline Q4 & White & Commercial-unknown & Peru \\
\hline Q5 & Black & Commercial-unknown & Peru \\
\hline Q6 & White & Commercial-unknown & Peru \\
\hline Q7 & Black & Commercial-unknown & Peru \\
\hline Q8 & White & Commercial-unknown & Peru \\
\hline Q9 & Black & Negra Collana & Peru \\
\hline Q10 & Red & Roja Pasankalla & Peru \\
\hline Q11 & White & Salcedo INIA & Peru \\
\hline Q12 & Red & Commercial-unknown & Peru \\
\hline Q13 & White & Blanca Kancolla & Peru \\
\hline Q14 & Red & Commercial-unknown & Peru \\
\hline Q15 & White & Commercial-unknown & Peru \\
\hline Q16 & White & Commercial-unknown & Peru \\
\hline Q17 & Red & Commercial-unknown & Peru \\
\hline Q18 & White & Commercial-unknown & Peru \\
\hline Q19 & Black & Commercial-unknown & Peru \\
\hline Q20 & Black & Commercial-unknown & Peru \\
\hline Q21 & White & Commercial-unknown & Peru \\
\hline Q22 & White & Commercial-unknown & Peru \\
\hline Q23 & White & Commercial-unknown & Peru \\
\hline Q24 & Black & Commercial-unknown & Peru \\
\hline Q25 & Black & Commercial-unknown & Peru \\
\hline Q26 & Red & Pasankalla & Peru \\
\hline Q27 & Red & Commercial-unknown & Peru \\
\hline Q28 & Red & Roja Pasankalla & Peru \\
\hline Q29 & White & Blanca Hualhuas & Peru \\
\hline Q30 & White & Commercial-unknown & Peru \\
\hline Q31 & White & Blanca Hualhuas & Peru \\
\hline Q32 & Red & Rosada de Huancayo & Peru \\
\hline Q33 & Black & Negra Pasankalla & Peru \\
\hline Q34 & Black & Commercial-unknown & Peru \\
\hline Q35 & Red & Commercial-unknown & Peru \\
\hline Q36 & Red & Commercial-unknown & Peru \\
\hline Q37 & White & Commercial-unknown & Spain \\
\hline Q38 & White & Commercial-unknown & Peru \\
\hline Q39 & White & Commercial-unknown & Peru \\
\hline
\end{tabular}

detailed nutritional (protein, fat, ash, carbohydrates and energy) and chemical (organic acids, free sugars, fatty acids, and tocopherols) characterization of the most common colour varieties of this species (i.e., red, black and white) from different origins (commercial and noncommercial varieties sourced from Peru and Spain) and, therefore, validate its consumption.

\section{Materials and methods}

\subsection{Samples}

Dry seeds (saponified by an unknown process) of distinct colour varieties (black, red and white) of Chenopodium quinoa Willd species (Chenopodiaceae) were provided by the National Agricultural University La Molina (Peru) for scientific purposes or obtained from commercial establishments in Peru and Spain. Relevant information of the 39 analysed samples is presented in Table 1 . For analysis, grains were reduced to a fine dried powder ( $\sim 20$ mesh) and mixed to obtain a homogeneous sampling.

\subsection{Nutritional value and chemical composition}

Nutritional value (protein, fat, carbohydrates and ash content) was determined according to AOAC procedures (AOAC, 2016), following methods described by Melgar et al. (2017). For the protein content evaluation, a macro-Kjeldahl method $(\mathrm{N} \times 6.25)$ was used; the crude fat was determined using a Soxhlet apparatus, extracting the sample with petroleum ether; ash content was estimated by incineration at
$600 \pm 15^{\circ} \mathrm{C}$ during $5 \mathrm{~h}$; total carbohydrates were calculated by difference; and the energy content was determined applying the equation: Energy $(\mathrm{kcal})=4 \times(\mathrm{g}$ protein $+\mathrm{g}$ carbohydrates $)+9 \times(\mathrm{g}$ fat $)$.

\subsection{Chemical composition}

The chemical composition regarding free sugars, organic acids, tocopherols, and fatty acids, was evaluated following a procedure previously described by Barros et al. (2013). Free sugars were determined by HPLC-RI (high performance liquid chromatography coupled to a refraction index detector) and data were analysed using Clarity 2.4 Software (DataApex, Podohradska, Czech Republic). Sugars standards $(\mathrm{D}(-)$-fructose, $\mathrm{D}(+)$-sucrose, $\mathrm{D}(+)$-glucose, $\mathrm{D}(+)$-trehalose, and $\mathrm{D}$ (+)-raffinose pentahydrate, Sigma-Aldrich, St. Louis, MO, USA) were used for identification by chromatographic comparison. Quantification was achieved using the internal standard (melezitose) method and the results were expressed in $\mathrm{g}$ per $100 \mathrm{~g}$ of dry weight (dw).

Organic acids were analysed using UFLC (Ultra-Fast Liquid Chromatography; Shimadzu 20A series, Kyoto, Japan) and a photodiode array detector. Organic acids standards $(L(+)$-ascorbic acid, citric acid, malic acid, oxalic acid, shikinic acid, succinic acid, fumaric acid, and quinic acid; Sigma-Aldrich, St. Louis, MO, USA) were used for identification by performing chromatographic comparisons with the samples' peaks. These standards were also used for the quantification, using the external standard methodology. The results were expressed in mg per $100 \mathrm{~g}$ of dry weight $(\mathrm{dw})$.

Tocopherols were identified by HPLC connected to a fluorescence detector (FP-2020; Jasco) programmed for excitation at $290 \mathrm{~nm}$ and emission at $330 \mathrm{~nm}$. The isoforms present in the sample were identified by chromatographic comparisons with authentic standards $(\alpha-, \beta-, \gamma-$, and $\delta$-tocopherols; Matreya, Pleasant Gap, PA, USA), using a Clarity 2.4 Software (DataApex, Podohradska, Czech Republic). The quantification was based on the fluorescence signal response, using the internal standard method (tocol, $50 \mathrm{mg} / \mathrm{mL}$; Matreya, Pleasant Gap, PA, USA). The results were expressed in $\mu \mathrm{g}$ per $100 \mathrm{~g}$ of dry weight (dw).

Fatty acids content was determined using GC-FID (gas-liquid chromatography with flame ionization detection) with a capillary column. The compounds were identified comparing the relative retention times of FAME peaks from samples with standards (FAME mixture, standard 47885-U, Sigma-Aldrich, St. Louis, MO, USA). The results were recorded and processed using the CSW 1.7 Software (DataApex 1.7, Prague, Czech Republic) and were expressed in percentage (\%).

\subsection{Statistical analysis}

For each of the compounds, the functions $I m$ and anova were used to adjust an analysis of variance testing for any effect of quinoa colour varieties. The lsmeans library was also used to compute the least square means (LSM) and LSM-pairwise comparisons between quinoa colour varieties using the Tukey's Honestly Significant Difference test. All the functions were implemented in the R software (version 3.4.4, R Core Team, Austria).

\section{Results and discussion}

For the discussion and presentation of the results, the 39 quinoa samples were grouped by colour variety (black, white and red) in the tables. In total, there were 9 black samples, 19 white samples, and 11 red samples. The identification of the samples is presented in Table 1.

\subsection{Nutritional value}

The results regarding the nutritional value of the 39 quinoa samples of three colour varieties are presented in Table 2 .

Taking into account the obtained values, it was evident that in all quinoa samples carbohydrates was the major macronutrient, followed 
Table 2

Nutritional value of the evaluated types of dry seeds of Chenopodium quinoa Willd. Concentrations are presented as mean \pm SE.

\begin{tabular}{|c|c|c|c|c|c|c|}
\hline Sample type & Moisture (g/100 g fw) & Ash $(\mathrm{g} / 100 \mathrm{~g} \mathrm{dw})$ & Proteins $(\mathrm{g} / 100 \mathrm{~g} \mathrm{dw})$ & Fat $(\mathrm{g} / 100 \mathrm{~g} \mathrm{dw})$ & Carbohydrates (g/100 g dw) & Energy (kcal/100 g dw) \\
\hline Black & $9.7 \pm 0.3$ & $2.7 \pm 0.2$ & $14.6 \pm 0.4 \mathrm{ab}$ & $6.8 \pm 0.3$ & $76.1 \pm 0.5 a$ & $424 \pm 2$ \\
\hline Red & $9.6 \pm 0.2$ & $2.8 \pm 0.2$ & $15.6 \pm 0.4 a$ & $6.4 \pm 0.3$ & $75.3 \pm 0.5 b$ & $420 \pm 2$ \\
\hline White & $9.3 \pm 0.2$ & $2.6 \pm 0.1$ & $14.4 \pm 0.3 b$ & $6.0 \pm 0.2$ & $77.0 \pm 0.3 a$ & $420 \pm 1$ \\
\hline$(\mathrm{n}=117) \quad$ ANOVA $p$-value ${ }^{1}$ & 0.3377 & 0.3999 & 0.02531 & 0.0761 & 0.01209 & 0.2561 \\
\hline
\end{tabular}

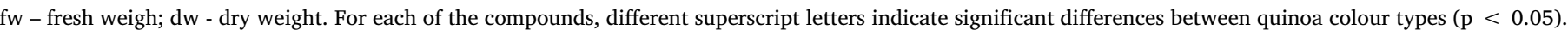

1 If $p<0.05$, at least one of the quinoa types has a significantly different value for that parameter.

Table 3A

Free sugars composition of the evaluated types of dry seeds of Chenopodium quinoa Willd. Concentrations are presented in dry weight (dw) as mean \pm SE.

\begin{tabular}{|c|c|c|c|c|c|}
\hline Sample code & Arabinose $(\mathrm{g} / 100 \mathrm{~g} \mathrm{dw})$ & Fructose $(\mathrm{g} / 100 \mathrm{~g} \mathrm{dw})$ & Glucose $(\mathrm{g} / 100 \mathrm{~g} \mathrm{dw})$ & Sucrose $(\mathrm{g} / 100 \mathrm{~g} \mathrm{dw})$ & Total $(\mathrm{g} / 100 \mathrm{~g} \mathrm{dw})$ \\
\hline Black & $0.50 \pm 0.05$ & $0.27 \pm 0.05$ & $0.64 \pm 0.08$ & $1.7 \pm 0.3$ & $3.1 \pm 0.3$ \\
\hline Red & $0.63 \pm 0.04$ & $0.20 \pm 0.05$ & $0.47 \pm 0.09$ & $1.3 \pm 0.2$ & $2.6 \pm 0.2$ \\
\hline White & $0.62 \pm 0.03$ & $0.25 \pm 0.04$ & $0.61 \pm 0.07$ & $1.4 \pm 0.2$ & $2.9 \pm 0.1$ \\
\hline$(\mathrm{n}=117)$ ANOVA $p$-value ${ }^{1}$ & 0.1362 & 0.6254 & 0.4157 & 0.4805 & 0.3546 \\
\hline
\end{tabular}

1 If $p<0.05$, at least one of the quinoa types has a significantly different value for that parameter.

by protein, fat and ash. Moisture showed values between 9.3 and $9.7 \mathrm{~g} /$ $100 \mathrm{~g} \mathrm{fw}$, exhibiting no significant differences between colour varieties (p > 0.05).

Carbohydrates content fluctuated between 75.3 and $77.0 \mathrm{~g} / 100 \mathrm{~g}$ $\mathrm{dw}$, being white and black varieties the samples that presented slightly higher mean concentrations ( 77.0 and $76.1 \mathrm{~g} / 100 \mathrm{~g} \mathrm{dw}$, respectively). On the other hand, the protein content oscillated between 14.4 and $15.6 \mathrm{~g} / 100 \mathrm{~g} \mathrm{dw}$, showing no statistically significant differences ( $p>0.05)$ among the different studied samples. In addition to their nutritional value, the proteins of quinoa have been suggested to exert some beneficial effects and to be a source of bioactive peptides (Vilcacundo, Miralles, Carrillo, \& Hernández-Ledesma, 2018).

The mean fat contents of the black, white and red grains were not statistically different, spanning only from 6.0 to $6.8 \mathrm{~g} / 100 \mathrm{~g} \mathrm{dw}$. Likewise, the ash content also came out to be homogeneous in the three coloured-grain quinoa with mean values of $2.6-2.8 \mathrm{~g} / 100 \mathrm{~g} \mathrm{dw}$.

The macronutrients composition of this seed has arouse interest among both producers and consumers, which have prompted the conduction of several scientific studies investigating on its high nutritional quality and its myriad of potential uses. To name some, Encina-Zelada et al. (2017) studied the composition of several Peruvian samples of Chenopodium quinoa Wild grains by Near-Infrared Transmission Spectroscopy and their results were, generally, similar to the results obtained in the present study. Regarding fat, ash, carbohydrate and moisture, the contents were very comparable $(6.54,3.13,8.45$ and $10.55 \mathrm{~g} / 100 \mathrm{~g} \mathrm{dw}$, respectively), whereas for the protein content these authors obtained lower values $(9.88 \mathrm{~g} / 100 \mathrm{~g} \mathrm{dw})$.

The same happened in studies carried out by Repo-CarrascoValencia, Hellström, Pihlava, and Mattila (2010), where the composition of quinoa was studied through the same methodologies used in the present study; in a study performed by Ferreira, Pallone, and Poppi (2015) (direct analysis of the main chemical constituents of Chenopodium quinoa grains using Fourier transform near-infrared spectroscopy), and in a review of nutritional and health benefits of Chenopodium quinoa Willd performed by Navruz-Varli and Sanlier (2016). While the former two studies reported proximate analysis results comparable with those of the present study; the latter article reported carbohydrate $(64 \mathrm{~g} / 100 \mathrm{~g} \mathrm{dw})$ and energy contents (368 Kcal) that considerably differed from those found in this study (with mean values of $76 \mathrm{~g} / 100 \mathrm{~g} \mathrm{dw}$ and $420 \mathrm{kcal} / 100 \mathrm{~g} \mathrm{dw}$ for carbohydrate and energy, respectively). Such oscillation in the nutritional value is not unexpected, and can be explained not only by the different varieties of quinoa, but also by the varying agronomic factors such as concentration of minerals in the cultivation soil, and the application of fertilizers (Nowak et al., 2016).

Particularly in relation to moisture, the study carried out by Ferreira et al. (2015) revealed a great heterogeneity compared to the present study, presenting concentrations that span from 25 to $33 \mathrm{~g} / 100 \mathrm{~g} \mathrm{dw}$. However, the differences observed, could be due to the different methodologies used in the drying process (Encina-Zelada et al., 2017), storage forms, and the storage time prior to the analysis. It can also be explained by the geographic differences where the quinoa samples were cultivated, because the environment factors have a great influence in the nutritional and chemical composition of plant species (Champpel et al., 2017).

\subsection{Chemical composition}

The chemical composition in sugars was also analysed and the results are shown in Table 3A. Arabinose, fructose, glucose and sucrose were the sugars found in the 39 quinoa samples, being sucrose the principal sugar in all types of quinoa (black, red and white). Nonetheless, no statistically significant differences $(p>0.05)$ were found between the mean values obtained of sucrose concentration, which ranged from 1.3 to $1.7 \mathrm{~g} / 100 \mathrm{~g} \mathrm{dw}$. Arabinose, fructose and glucose were quantified in mean concentrations of $0.50-0.63,0.20-0.27$ and $0.47-0.64 \mathrm{~g} / 100 \mathrm{gdw}$, respectively, which suggests that these seeds regardless of the colour type have low glycemic index. Bringing all sugars together, the total contents was similar for the three colour types (2.6, 2.9 and $3.1 \mathrm{~g} / 100 \mathrm{~g} \mathrm{dw}$ for the same molecules, respectively). Thus, the statistical evaluation of the results showed that, in all of the detected molecules, there were no significant variations between black, red and white varieties. From these analyses, it can be also inferred that the commercial varieties of quinoa have practically a regular composition. Other authors that focused their study on the sugar profile of $C$. quinoa obtained slightly different results regarding the molecules identified.

Pellegrini et al. (2018) carried out studies on the physico-chemical characterization, techno-functional, in vitro antioxidant properties and total phenolic and flavonoids contents of six samples of quinoa flour, and only detected sucrose, glucose and fructose, in concentrations ranging from 1.11 to $1.52,0.59-0.80$ and $0.11-0.16 \mathrm{~g} / 100 \mathrm{~g} \mathrm{dw}$, respectively, for each molecule. However, sucrose is also the major sugar in the six samples.

On the other hand, Ogungbenle, Oshodi, and Oladimeji (2009), through studies on nutritional quality and functional activities of quinoa, detected other sugar molecules, such as, D-xylose $(120 \mathrm{mg}$ / $100 \mathrm{~g}$ sample) and maltose $(101.0 \mathrm{mg} / 100 \mathrm{~g}$ sample). These authors also obtained lower concentrations of glucose $(19.0 \mathrm{mg} / 100 \mathrm{~g}$ sample) and fructose (19.6 mg/100 g sample).

Vilcacundo and Hernández-Ledesma (2017), in order to study the 
Table 3B

Organic acids composition of the evaluated types of dry seeds of Chenopodium quinoa Willd. Concentrations are presented in dry weight (dw) as mean \pm SE.

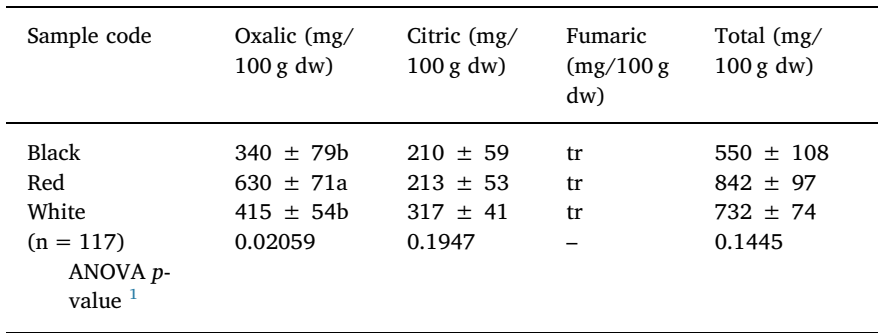

tr- traces. For each of the compounds, different superscript letters indicate significant differences between quinoa colour types $(\mathrm{p}<0.05)$.

${ }^{1}$ If $p<0.05$, at least one of the quinoa types has a significantly different value for that parameter.

nutritional and biological value of Chenopodium quinoa Wild seeds, revealed a total concentration of individual sugars of $3 \mathrm{~g} / 100 \mathrm{~g}$, as observed in the present study. Nevertheless, in addition to the discrepancy in glucose and fructose concentrations, they also detected other molecules, such as D-galactose and D-ribose. Moreover, maltose, D-galactose and D-ribose were also detected by Navruz-Varli and Sanlier (2016).

The differences in concentrations and, in particular, the different molecules detected, can be explained by the use of different quinoa varieties, the distinct geographical regions, and the different extraction methodologies used in the studies (for example, ultrasonic extraction and extraction performed with high temperature) (Pellegrini et al., 2018).

The organic acids detected in the three types of quinoa were oxalic, citric and fumaric acids (Table 3B). Oxalic acid stood out as the organic acid present in the highest concentrations in all colour varieties (black, red and white), fluctuating between 340 and $630 \mathrm{mg} / 100 \mathrm{~g} \mathrm{dw}$. This acid was the only one where statistically significant differences were detected, having the red seeds the highest concentration $(630 \mathrm{mg} / 100 \mathrm{~g}$ $\mathrm{dw}$ ), followed by white and black seeds with 415 and $340 \mathrm{mg} / 100 \mathrm{~g} \mathrm{dw}$, respectively. Oxalic acid has been associated with reduction of the availability of dietary Ca and several kidney diseases, such as calculus (Guil, Torija, Giménez, Rodríguez-García, and Giménez, 1996). Moreover, several authors have also reported a direct interference between oxalic acid and vitamins, namely vitamin C (Liu et al., 2018), leading to its oxidation.

The mean concentrations of citric acid were $317 \mathrm{mg} / 100 \mathrm{~g} \mathrm{dw}$ for white, $213 \mathrm{mg} / 100 \mathrm{~g} \mathrm{dw}$ for red and $210 \mathrm{mg} / 100 \mathrm{~g} \mathrm{dw}$ for black grains. Fumaric acid was quantified only in trace concentrations in the three types of quinoa samples. Thus, the mean concentrations of total organic acids were $550 \mathrm{mg} / 100 \mathrm{~g} \mathrm{dw}$ for the black grains, $732 \mathrm{mg} / 100 \mathrm{~g} \mathrm{dw}$ for the white grains and $842 \mathrm{mg} / 100 \mathrm{~g} \mathrm{dw}$ for the red grains.

Pellegrini et al. (2018) undertook a study on the chemical properties of quinoa flour and also detected several compounds of nutritional and bioactive interest, namely, organic acids. These authors identified oxalic (approximately $0.64 \mathrm{mg} / \mathrm{g}$ ) and citric acid (approximately $0.54 \mathrm{mg} / \mathrm{g}$ ), in concentrations that are in accordance with the present study; however, they also detected malic and succinic acid, showing the latter the highest amount (approximately $17 \mathrm{mg} / \mathrm{g}$ ).
With regards to the evaluation of tocopherols, the isoforms $\alpha$-, $\gamma$ and $\delta$-tocopherols were detected in the three quinoa colour varieties (Table 3C), although $\gamma$-tocopherol was the predominant isoform. The mean values showed a statistically significant oscillation $(\mathrm{p}<0.05)$, highlighting that the black grains contained the highest concentration $(1619 \mu \mathrm{g} / 100 \mathrm{~g} \mathrm{dw})$, followed by the red varieties $(1210 \mu \mathrm{g} / 100 \mathrm{~g} \mathrm{dw})$, and, lastly, the white varieties $(839 \mu \mathrm{g} / 100 \mathrm{~g} \mathrm{dw})$.

$\gamma$-Tocopherol represents a strong anti-inflammatory agent and can have equal or stronger antioxidant properties than $\alpha$-tocopherol. Foods containing high concentration of $\gamma$-tocopherol are well known for being able to lower the risks of cardiovascular diseases (Tang et al., 2015).

The remaining vitamers found, $\alpha$ - and $\delta$-tocopherol, did not reveal significant differences among the colour varieties studied, with mean concentrations at $128 \mu \mathrm{g} / 100 \mathrm{~g} \mathrm{dw}$ (black), $169 \mu \mathrm{g} / 100 \mathrm{~g} \mathrm{dw}$ (red) and $125 \mu \mathrm{g} / 100 \mathrm{~g} \mathrm{dw}$ (white) for the $\alpha$-isoform; and $17 \mu \mathrm{g} / 100 \mathrm{~g} \mathrm{dw}$ (black), $9 \mu \mathrm{g} / 100 \mathrm{~g} \mathrm{dw}$ (red) and $7 \mu \mathrm{g} / 100 \mathrm{~g} \mathrm{dw}$ (white) for the $\delta$-isoform. The total amount of tocopherols ranged between 971 and $1764 \mu \mathrm{g} / 100 \mathrm{~g} \mathrm{dw}$ in white and black varieties, respectively.

Tang et al. (2015) carried out a study that characterized the profile of tocopherols in seeds of three Chenopodium quinoa Wild genotypes, using also a HPLC-fluorescence system to detect and quantify its concentration. They were able to detect $\alpha$-, $\beta$-, $\gamma$-, and $\delta$-tocopherol, and, as in our study, they found out that $\gamma$-tocopherol constituted the main vitamer.

Although quinoa has a concentration of total tocopherols similar to other commonly consumed cereal grains, its individual tocopherol profile is different, distinguishing itself through the isoforms that appear in the major concentrations (Tang et al., 2015).

Fatty acids were another class of liposoluble compounds present in the studied varieties of quinoa seeds, whose results are displayed in Table 3D.

An evaluation of the fatty acid profile belonging to the black, red and white varieties was performed. Approximately 30 different fatty acids were detected (depending on the genotype), with values lower than $7 \%$; however, in the table only the major compounds are presented. Thus, C18:2n6 (linoleic acid), followed the C18:1n9 (oleic acid), and C16:0 (palmitic acid) stood out as the most important fatty acids, showing no significant differences $(p>0.05)$ among the different quinoa colour varieties. Various benefits have been reported for linoleic and oleic acids. In an epidemiological study, plasma linoleic acid was associated with decreased intra-myocellular lipid levels in older adults (Belury, Cole, Snoke, Banh, \& Angelotti, 2018). Also, oleic acid represents a benefit in human diet, by reducing the levels of low-density lipoprotein (LDL) in the blood, suppressing gerergenesis, improving inflammatory diseases and controlling blood pressure (Dhakal, Jung, Chae, Shannon, \& Lee, 2014).

The content of linoleic acid varied between 27 and 31\% in red and black varieties, respectively; while in oleic acid the variation was between approximately 33\% (red and white) and 32\% (black). The palmitic acid content ranged between 20\% (black and white) and $21 \%$ (red).

Taking into account their classification, the monounsaturated fatty acids (MUFA) presented the highest concentration (approximately $40 \%$ ), followed by polyunsaturated fatty acids (PUFA; $31-33 \%$ ), and lastly, saturated fatty acids (SFA; 27-29\%). Studies in humans indicate

Table 3C

Tocopherols composition of the evaluated types of dry seeds of Chenopodium quinoa Willd. Concentrations are presented in dry weight (dw) as mean \pm SE.

\begin{tabular}{|c|c|c|c|c|}
\hline Tocopherols & $\alpha$-Tocopherol $(\mu \mathrm{g} / 100 \mathrm{~g} \mathrm{dw})$ & $\gamma$-Tocopherol $(\mu \mathrm{g} / 100 \mathrm{~g} \mathrm{dw})$ & $\delta$-Tocopherol $(\mu \mathrm{g} / 100 \mathrm{~g} \mathrm{dw})$ & Total tocopherols $(\mu \mathrm{g} / 100 \mathrm{~g} \mathrm{dw})$ \\
\hline Black & $128 \pm 20$ & $1619 \pm 96 a$ & $17 \pm 7$ & $1764 \pm 144 a$ \\
\hline Red & $169 \pm 18$ & $1210 \pm 87 b$ & $9 \pm 6$ & $1388 \pm 103 a$ \\
\hline White & $125 \pm 13$ & $839 \pm 66 c$ & $7 \pm 5$ & $971 \pm 79 b$ \\
\hline$(\mathrm{n}=117)$ ANOVA $p$-value ${ }^{1}$ & 0.1256 & $<0.001$ & 0.4552 & $<0.001$ \\
\hline
\end{tabular}

For each of the compounds, different superscript letters indicate significant differences between quinoa colour types (p $<0.05$ ).

${ }^{1}$ If $p<0.05$, at least one of the quinoa types has a significantly different value for that parameter. 
Table 3D

Major fatty acids (values $\geq 5 \%$ in all species) of the thirty-nine evaluated types of dry seeds of Chenopodium quinoa Willd. The results are presented in relative percentage as mean $\pm \mathrm{SE}$.

\begin{tabular}{lllllll}
\hline Sample code & C16:0 & C18:1n9 & C18:2n6 & SFA & MUFA & PUFA \\
\hline Black & $20 \pm 2$ & $32 \pm 3$ & $31 \pm 5$ & $27 \pm 4$ & $40 \pm 3$ & $33 \pm 6$ \\
Red & $21 \pm 2$ & $33 \pm 2$ & $27 \pm 5$ & $29 \pm 3$ & $40 \pm 3$ & $31 \pm 5$ \\
White & $20 \pm 2$ & $33 \pm 2$ & $30 \pm 4$ & $27 \pm 2$ & $40 \pm 2$ & $33 \pm 4$ \\
$\begin{array}{c}(\mathrm{n}=117) \text { ANOVA } \\
\quad \text {-value }^{1}\end{array}$ & 0.8372 & 0.9693 & 0.8776 & 0.8772 & 0.9909 & 0.9458 \\
& & & & & & \\
\hline
\end{tabular}

Approximately 30 different fatty acids were detected (depending of species), with values lower than 7\%; and C16:0 (palmitic acid), C18:1n9 (oleic acid), and C18:2n6 (linoleic acid) were the fatty acids present in higher concentration. SFA (saturated fatty acids), MUFA (monounsaturated fatty acids), PUFA (polyunsaturated fatty acids).

${ }^{1}$ If $p<0.05$, at least one of the quinoa types has a significantly different value for that parameter.

that diets rich in MUFA have protective effects on cardiovascular risk, non-alcoholic fatty liver disease and diabetes (Chen et al., 2018).

These results are in agreement with a study performed by Tang et al. (2015), who indicated that linoleic and oleic are the major acids in black, red and white quinoa; yet at higher concentrations (47-49\% and $25-29 \%$, respectively). In this study, the total fatty acids amount was higher in the red varieties, whereas for all colour varieties PUFA concentration (54-58\%) was followed by MUFA (29-33\%), and finally by SFA (10-11\%).

The same was evidenced in a study conducted by Pellegrini et al. (2018), which also reported quinoa samples to be rich in C16:0 (8-9\%), C18:1n9 (25-27\%) and C18:2 (48-52\%); with PUFA in higher concentrations (55 and 60\%) than both MUFA (29-33\%) and SFA (10-11\%).

\section{Conclusion}

Quinoa seeds have been shown scientific interest, having potentiated several studies on nutritional composition; however, the majority of reports have mainly addressed protein evaluation and characterization. The present study evaluated three colour varieties of quinoa (black, red and white), detecting several compounds of nutritional interest that can be paramount in promoting the consumption of this pseudocereal.

The results showed that, in the nutritional composition, the content of proteins and carbohydrates stood out, whereas among the hydrosoluble compounds sucrose and oxalic acid were present in higher concentrations. On the other hand, and completing this evaluation with the determination of liposoluble compounds, the presence of tocopherols and fatty acids was evident, being the $\gamma$-tocopherol the main isoform, and the linoleic acid the unsaturated fatty acid found in highest concentrations.

In relation to the different colour varieties studied, statistical analysis pointed out significant differences only in proteins, carbohydrates, oxalic acid, $\gamma$-tocopherol and total tocopherol contents. This can be a consequence of the inherent genetic variability of the samples, but also the forms and time of storage and the agronomic conditions where they were cultivated.

Thus, quinoa seeds have been demonstrated to be clearly an excellent choice for the diet of consumers, exhibiting not only high nutritional profile but also a composition in molecules of high interest, such as, tocopherols and organic acids, which promotes bioactive benefits for the organism.

\section{Acknowledgements}

The authors are grateful to the Foundation for Science and
Technology (FCT, Portugal) and FEDER under Programme PT2020 for financial support to CIMO (UID/AGR/00690/2013), L. Barros and U. Gonzales-Barron contracts.

\section{Conflict of interest}

The authors declare no conflict of interest.

\section{References}

AOAC, 2016. AOAC Official methods of analysis, 20th Ed. AOAC International.

Abderrahim, F., Huanatico, E., Segura, R., Arribas, S., Gonzalez, M. C., \& Condezo-Hoyos, L. (2015). Physical features, phenolic compounds, betalains and total antioxidant capacity of coloured quinoa seeds (Chenopodium quinoa Willd.) from Peruvian Altiplano. Food Chemistry, 183, 83-90.

Aziz, A., Akram, N. A., \& Ashraf, M. (2018). Influence of natural and synthetic vitamin C (ascorbic acid) on primary and secondary metabolites and associated metabolism in quinoa (Chenopodium quinoa Willd.) plants under water deficit regimes. Plant Physiology and Biochemistry, 123, 192-203.

Barros, L., Pereire, E., Calhelha, R. C., Duenas, M., Carvalho, A. M., Santos-Buelga, C., \& Ferreira, I. C. F. R. (2013). Bioactivity and chemical characterization in hydrophilic and lipophilic compounds of Chenopodium ambrosioides L. Journal of Function Foods, 5, 1732-1740.

Belury, M. A., Cole, R. M., Snoke, D. B., Banh, T., \& Angelotti, A. (2018). Linoleic acid, glycemic control and type 2 diabetes. Prostaglandins, Leukotrienes and Essential Fatty Acids, 132, 30-33.

Chappell, A., Scott, K. P., Griffiths, I. A., Cowan, A. A., Hawes, C., Wishart, J., \& Martin, P. (2017). The agronomic performance and nutritional content of oat and barley varieties grown in a northern maritime environment depends on variety and growing conditions. Journal of Cereal Science, 74, 1-10.

Chen, X., Li, L., Liu, X., Luo, R., Liao, G., Li, L., ... Chen, Y. (2018). Oleic acid protects saturated fatty acid mediated lipotoxicity in hepatocytes and rat of non-alcoholic steatohepatitis. Life Sciences, 203, 291-304.

Dhakal, K. H., Jung, K.-H., Chae, J.-H., Shannon, J. G., \& Lee, J.-D. (2014). Variation of unsaturated fatty acids in soybean sprout of high oleic acid accessions. Food Chemistry, 164, 70-73.

Encina-Zelada, C., Cadavez, V., Pereda, J., Gómez-Pando, L., Salvá-Ruíz, B., Teixeira, J. A., ... Gonzales-Barron, U. (2017). Estimation of composition of quinoa (Chenopodium quinoa Willd.) grains by Near-Infrared Transmission spectroscopy. LWT - Food Science and Technology, 79, 126-134.

Ferreira, D. S., Pallone, J. A. L., \& Poppi, R. J. (2015). Direct analysis of the main chemical constituents in Chenopodium quinoa grain using Fourier transform near-infrared spectroscopy. Food Control, 48, 91-95.

Gómez-Caravaca, A. M., Iafelice, G., Verardo, V., Marconi, E., \& Caboni, M. F. (2014) Influence of pearling process on phenolic and saponin content in quinoa (Chenopodium quinoa Willd). Food Chemistry, 157, 174-178.

Guil, J. L., Torija, M. E., Giménez, J. J., Rodríguez-García, I., \& Giménez, A. (1996). Oxalic acid and calcium determination in wild edible plants. Journal of Agricultural and Food Chemistry, 44, 1821-1823.

Hu, Y., Zhang, J., Zoua, L., Fub, C., Lic, P., \& Zhao, G. (2017). Chemical characterization, antioxidant, immune-regulating and anticancer activities of a novel bioactive polysaccharide from Chenopodium quinoa seeds. International Journal of Biological Macromolecules, 99, 622-629.

Küster, I., \& Vila, N. (2017). Health/Nutrition food claims and low-fat food purchase: projected personality influence in young consumers. Journal of Functional Foods, 38, 66-76.

Li, G., \& Zhu, F. (2018). Quinoa starch: structure, properties, and applications. Carbohydrate Polymers, 181, 851-861.

Liu, T. T., et al. (2018). Inhibitory mechanism and molecular analysis of furoic acid and oxalic acid on lípase. International Journal of Biological Macromolecules, 120, 1925-1934.

Melgar, B., et al. (2017). Extensive profiling of three varieties of Opuntia spp. fruit for innovative food ingredients. Food Research International, 101, 259-265.

Navruz-Varli, S., \& Sanlier, N. (2016). Nutritional and health benefits of quinoa (Chenopodium quinoa Willd.). Journal of Cereal Science, 69, 371-376.

Nowak, V., Du, J., \& Charrondière, U. R. (2016). Assessment of the nutritional composition of quinoa (Chenopodium quinoa Willd.). Food Chemistry, 193, 47-54.

Ogungbenle, H. N., Oshodi, A. A., \& Oladimeji, M. O. (2009). The proximate and effect of salt applications on some functional properties of quinoa (Chenopodium quinoa) flour. Pakistan Journal of Nutrition, 8, 49-52.

Pellegrini, M., Lucas-Gonzales, R., Ricci, A., Fontecha, J., Fernández-López, J., PérezÁlvarez, J. A., \& Viuda-Martos, M. (2018). Chemical, fatty acid, polyphenolic profile, techno-functional and antioxidant properties of flours obtained from quinoa (Chenopodium quinoa Willd) seeds. Industrial Crops \& Products, 111, 38-46.

Repo-Carrasco-Valencia, R., Hellström, J. K., Pihlava, J.-M., \& Mattila, P. H. (2010). Flavonoids and other phenolic compounds in Andean indigenous grains: Quinoa (Chenopodium quinoa), kañiwa (Chenopodium pallidicaule) and kiwicha (Amaranthus caudatus). Food Chemistry, 120, 128-133.

Tang, Y., Li, X., Zhang, B., Chen, P. X., Liu, R., \& Tsao, R. (2015). Characterisation of phenolics, betanins and antioxidant activities in seeds of three Chenopodium quinoa Willd. genotypes. Food Chemistry, 166, 380-388.

Vilcacundo, R., \& Hernández-Ledesma, B. (2017). Nutritional and biological value of quinoa (Chenopodium quinoa Willd.). Current Opinion in Food Science, 14, 1-6.

Vilcacundo, R., Miralles, B., Carrillo, W., \& Hernández-Ledesma, B. (2018). In vitro chemopreventive properties of peptides released from quinoa (Chenopodium quinoa Willd.) protein under simulated gastrointestinal digestion. Food Research International, 105, 403-411. 